\title{
Photodynamic Therapy for Medication-Related Osteonecrosis of the Jaws: A Case Report
}

\author{
Mônica Simões Israel, Sarah Aparecida Antero, Gisele Cuba Riche, Giulianna Lima Pinheiro, \\ Mayara Leonel Duarte Meira, Fernanda Vieira Heimlich, Wagner Pinto das Chagas, \\ Nathália de Almeida Freire, Maria Eliza Barbosa Ramos, Rosemiro de Menezes Maciel
}

School of Dentistry, Rio de Janeiro State University, Rio de Janeiro, Brazil

Email: monicasisrael@yahoo.com.br

How to cite this paper: Israel, M.S., Antero, S.A., Riche, G.C., Pinheiro, G.L., Meira, M.L.D., Heimlich, F.V., das Chagas, W.P., de Almeida Freire, N., Ramos, M.E.B. and de Menezes Maciel, R. (2016) Photodynamic Therapy for Medication-Related Osteonecrosis of the Jaws: A Case Report. International Journal of Clinical Medicine, 7, 824-828.

http://dx.doi.org/10.4236/ijcm.2016.712089

Received: July 29, 2016

Accepted: December 20, 2016

Published: December 23, 2016

Copyright $\odot 2016$ by authors and Scientific Research Publishing Inc. This work is licensed under the Creative Commons Attribution International License (CC BY 4.0).

http://creativecommons.org/licenses/by/4.0/ (c) (i) Open Access

\begin{abstract}
Medication-related osteonecrosis of the jaws (MRONJ) is a relatively new disease. MARX reported first cases in 2003. MRONJ relates to oral and parenteral bisphosphonates as well as to the so-called target cancer therapies but the list of medications only grows. Although MRONJ is a relatively rare condition, it can be associated to significant morbidity with feeding limitations and intense pain. More severe cases can lead to potentially life-threatening infections. Every patient initiating bisphosphonate and/or target cancer therapy must visit a dentist before starting medication because preventive measures for MRONJ are much more effective compared to surgical management of the lesions. Surgical resolution can be especially difficult to obtain in the coexistence of certain complication factors like wider bone exposures, history of nitrogen containing bisphosphonates use (mainly zolendronate) and immunodeficiency. Recently, researchers have given attention to laser therapy associated to photosensitive agents as a possible option to management of some MRONJ lesions. Our case report demonstrates the use of photodynamic therapy in a denosumab related lesion in the mandible. It seems that denosumab related lesions are more amenable to treatment and total resolution because of the marked differences between its chemical and metabolic characteristics when compared to bisphosphonates.
\end{abstract}

\section{Keywords}

Laser, Phototherapy, Osteonecrosis, Jaws, Denosumab

\section{Introduction}

Medication-related osteonecrosis of the jaws (MRONJ) is a relatively new disease; 
MARX reported the first cases related to parenteral bisphosphonate in 2003 [1]. Later, a relation between MRONJ and oral bisphosphonates was established. More recently, medications like denosumab, used for the so-called target cancer therapies, received attention. Denosumab is a fully human monoclonal antibody that binds the cytokine RANKL (receptor activator of NF $k \mathrm{~B}$ ligand), an essential factor initiating bone turnover. RANKL inhibition blocks osteoclast maturation, function and survival, thus reducing bone resorption [2].

Although considered a rare condition, MRONJ can be associated to significant morbidity. Lesions can begin in an insidious, asymptomatic fashion and then lead to intense pain in the affected bone (mostly the mandible, but maxilla can be affected too), bone exposure, draining pus, fistula formation, feeding limitations and pathological fracture [3] [4]. Carrying out surgical procedures to heal MRONJ lesions can be a very frustrating experience for the surgeon. This can be especially true in the coexistence of certain complication factors like wider bone exposures, history of nitrogen containing bisphosphonates using (mainly zolendronate) and immunodeficiency [1].

Recently, researchers have given attention to laser therapy associated to photosensitive agents as a possible option to management of some MRONJ lesions. Promising results have been reached by using Chimiolux $0.005 \%{ }^{\circledR}$ (methylene blue; DMC) and posterior laser exposure.

\section{Case Report}

On February 2015, A.D.A, male, 83 years old, attended to FOUERJ complaining about "mild pain" in the lingual aspect of cortical bone near the lower right 3 during the last 4 months. History of denosumab use once a month until September 2014 for prevention of bone metastasis associated to prostate cancer was present. After removing upper and lower dentures, clinical examination revealed a painful area of exposed bone associated to pus drainage near the lower right 3 in association with a trauma of lower prosthesis in the region (Figure 1). Panoramic radiography showed an osteolytic lesion near the lower right 3 (Figure 2). The diagnostic of medication-related osteonecrosis of the jaws was clinically established. Initial management consisted in topical chlorhexidine 3 times a Day, after each brushing and penicillin intake Clavulin $875 \mathrm{mg}$ (makes use of 1 tablet, 12 in 12 hours for 7 consecutive days). After almost 3 months patient related no pain and pus drainage disappeared. On July 2015, fifteen low level laser therapy (LLLT) were initiated. The laser therapy was used aiming at soft tissue repair (red laser), bone biostimulation (infrared laser), and nerve repair (infrared laser) for pain relief. The lowlevel laser therapy equipment used was XT Therapy, produced by DMC, emits red and infrared laser light to the anti-inflammatory, analgesic, bio stimulant and healing purposes. The infrared laser has a wavelength of $808 \mathrm{~nm} \pm 10 \mathrm{~nm}$ the power output of the transmitter is $100 \mathrm{~mW} \pm 20 \%$. The red laser wavelength of $660 \mathrm{~nm} \pm 10 \mathrm{~nm}$ the power output of the transmitter is $100 \mathrm{~mW} \pm 20 \%$. The equipment used is contraindicated in pregnant patients or who are breastfeeding, with episode of skin cancer in the irradiated region patients, glaucoma patients, patients with cataracts that are not under 


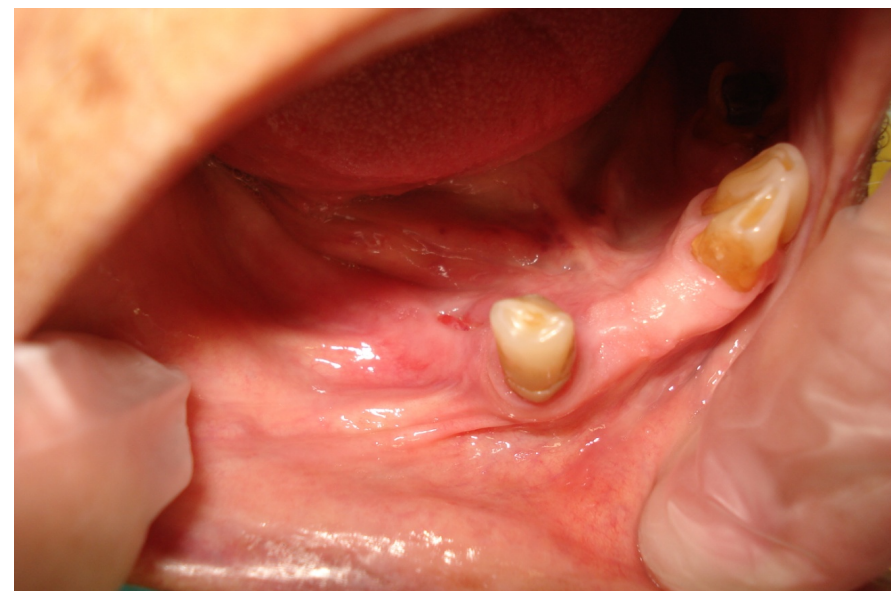

Figure 1. Clinical aspect with pus drainage near the lower right 3.

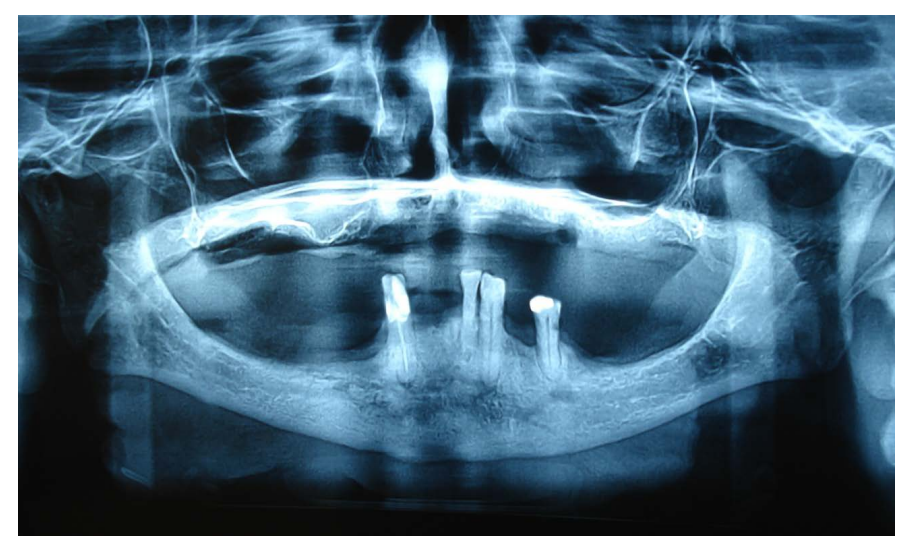

Figure 2. Panoramic radiography showing an osteolytic lesion near the lower right 3.

medical supervision. The low-power laser emits radiation without destructive potential and therapeutic effects on tissues. When used in combination with dyes has the potential to produce death of microorganisms in a process known as photodynamic therapy (PDT-Photodynamic therapy) [1]. At the first session was held photodynamic therapy (PDT) that used the Chimiolux $0.005 \%$ as photosensitizer. The Chimiolux was used at a concentration of $0.005 \%$ (Chimiolux 5) of methylene blue. In combination with red laser irradiation, the Chimiolux acts as photodynamic therapy (PDT) generating release of free radicals that provide bactericidal effect in contaminated areas. The application protocol followed the DMC laser manufacturer's recommendations: initially enters the solution from $0.005 \%$ methylene blue, then it is expected over 5 minutes (pre-irradiation time), then it proceeds to the red laser irradiation. The wavelength is $660 \mathrm{~nm}$, a fluence of $320 \mathrm{~J} / \mathrm{cm}^{2}$ or power $9 \mathrm{~J}$, a power of $100 \mathrm{~mW}$, the application time of 90 seconds. Finally removes the photosensitizing agent with sterile saline irrigation. The laser's exposure was made weekly for a total of 15 treatment sessions. The irradiated area was 6 $\mathrm{cm}^{2}$. The application protocol was given as follows: The infrared laser has a wavelength of $808 \mathrm{~nm}$ used in continuous mode and scan $2 \mathrm{~mm}$ distance to the mucosa to be irra- 
diated, and the laser red has a wavelength of $808 \mathrm{~nm}$ irradiating at three points to one $\mathrm{cm}$ distance between them, or used the red ray with infrared radiating at three points with one $\mathrm{cm}$ distance between them. The power used with both the infrared laser as with laser red was $100 \mathrm{~mW}$, varying only the fluence or power and the application time. The second session: $1 \mathrm{~J}$ red beam with infrared ray third, fourth and fifth session: $2 \mathrm{~J}$ with the red beam the sixth to tenth session: $2 \mathrm{~J}$ with the red beam and $4 \mathrm{~J}$ infrared ray Section 11:2 J red beam with the infrared ray. Thirteenth, fourth and fifth session: $2 \mathrm{~J}$ red beam with infrared ray and added $3 \mathrm{~J}$ with infrared ray in two oral extra points in the region of submentonianos lymph node in order to stimulate the defense of organism. In October 2015 panoramic examination showed kidnapping bony (Figure 3). There was good healing, without signs of infection and the presence of overlying mucosa under sequestration (Figure 4). Finally, on January 2016 spontaneous sequestration occurred with subsequent mucosal healing. Now, patient is clinically stable; free of signs and symptoms. The chlorhexidine gel is maintained and the management strategy was to conduct periodic follow-up radiographic evaluation.

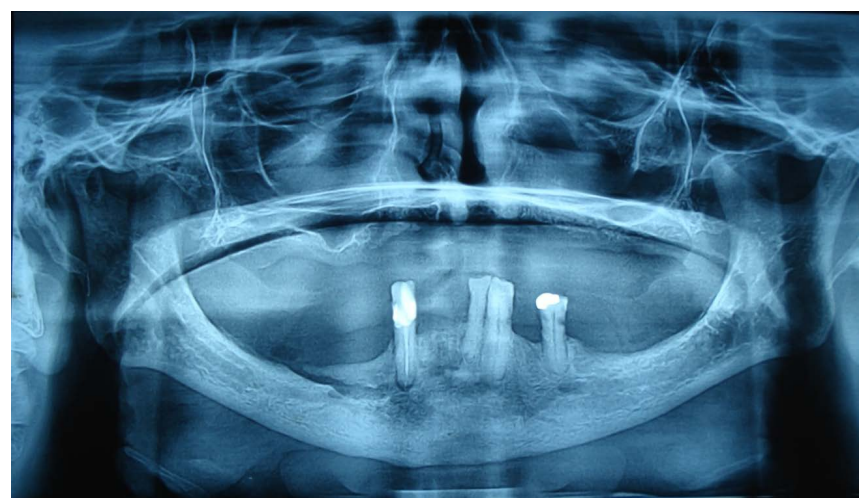

Figure 3. Panoramic radiography showing kidnapping bony near the lower right 3.

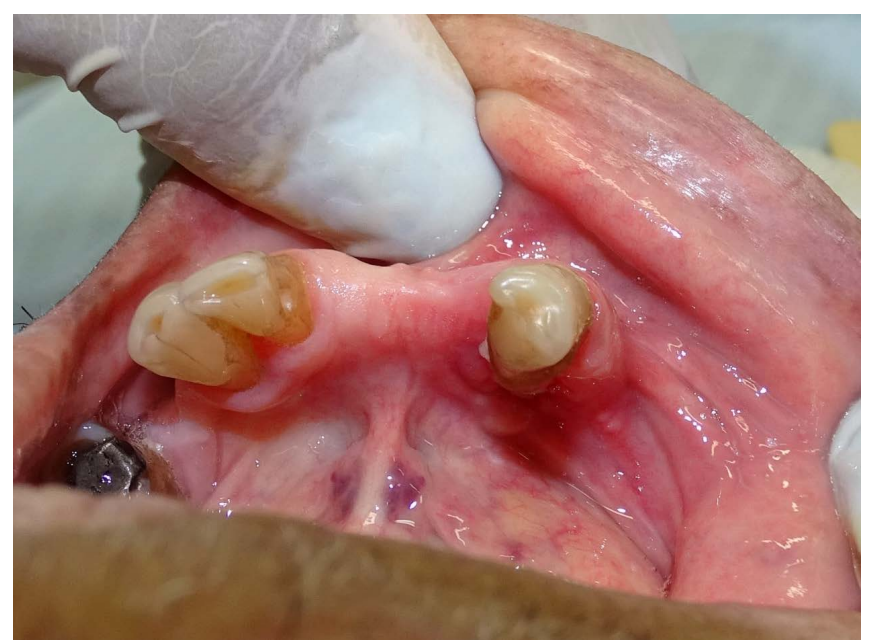

Figure 4. Clinical aspect showing good healing, without signs of infection and the presence of overlying mucosa under sequestration. 


\section{Discussion}

Until now cases associated to bisphosphonates therapies are not only the most common ones, but also the most difficult to manage. SMEETS et al., 2015 enfatized some important issues: the ten years bisphosphonates estimated half-life, the capacity of some of these drugs to lead to osteoclasts apoptosis, the alarming raising of prescriptions (including bisphosphonates indicated to osteopenia), the enhancement of drug-presentation leading to highly potent bisphosphonates, for example Aclasta ${ }^{\oplus}$, Reclast $^{\circledR}$ and the presence of bisphosphonates in uncountable day by day products. These factors are supposedly related to spread of cases worldwide [5].

Lesions related to denosumab seem to be more amenable to treatment and total resolution because of its chemical and metabolic characteristics (temporary inhibition of RANKL) [6]. It is important to differentiate MRONJ from other diseases like periodontal disease, necrotizing periodontal diseases, bone malignancies, osteomyelitis and herpes zoster virus related osteonecrosis. Obviously, applying different therapies to different causes of jaws osteonecrosis is mandatory [1]. We insist on recommending that every patient initiating bisphosphonate and/or target cancer therapy must visit a dentist before starting medication. Preventive measures for MRONJ are indispensable and much more effective compared to surgical management after developing of lesions.

\section{References}

[1] Ruggiero, S.L., Dodson, T.B., Fantasia, J., et al. (2014) American Association of Oral and Maxillofacial Surgeons Position Paper on Medication-Related Osteonecrosis of the Jaw2014 Update. JOMS, 72, 1938-1956.

[2] Aghaloo, T.L., Felsenfeld, A.L. and Tetradis, S. (2010) Osteonecrosis of the Jaw in a Patient on Denosumab. JOMS, 68, 959-963. https://doi.org/10.1016/j.joms.2009.10.010

[3] Ascani, G., Campisi, G. and Gutierrez, L.M.J. (2014) Current Controversies in Classification, Management and Prevention of Bisphosphonate-Related Osteonecrosis of the Jaw. International Journal of Dentistry, 2014, Article ID: 565743.

https://doi.org/10.1155/2014/565743

[4] Sivolella, S., Lumachi, F., Stellini, E., et al. (2013) Denosumab and Anti-Angiogenetic Drug Related Osteonecrosis of the Jaw: An Uncommon but Potentially Severe Disease. Anticancer Research, 33, 1793-1797.

[5] Smeets, R., Hanken, H., Jung, O. and Heiland, M. (2015) Future Perspectives of Bisphosphonates in Maxillofacial, Dental and Medical Practice. In: Otto, S., Ed., MedicationRelated Osteonecrosis of the Jaws. Bisphosphonates, Denosumab and New Agents, Springer, 207-215.

[6] Baron, R., Ferrari, S. and Russell, R.G. (2011) Denosumab and Bisphosphonates: Different Mechanisms of Action and Effects. Bone, 48, 677-692.

https://doi.org/10.1016/j.bone.2010.11.020 
Submit or recommend next manuscript to SCIRP and we will provide best service for you:

Accepting pre-submission inquiries through Email, Facebook, LinkedIn, Twitter, etc. A wide selection of journals (inclusive of 9 subjects, more than 200 journals)

Providing 24-hour high-quality service

User-friendly online submission system

Fair and swift peer-review system

Efficient typesetting and proofreading procedure

Display of the result of downloads and visits, as well as the number of cited articles

Maximum dissemination of your research work

Submit your manuscript at: http://papersubmission.scirp.org/

Or contactijcm@scirp.org 